\title{
A STUDY ON FRACTURE RESISTANCE OF CLASS IV CAVITIES TREATED WITH PINS
}

\author{
E. Boteva ${ }^{1}$, K. Peycheva ${ }^{1}$, D. Karayasheva ${ }^{1}$, D. Pashkouleva ${ }^{2}$ and M. Marinova ${ }^{1}$ \\ ${ }^{1}$ Department of Conservative Dentistry, Faculty of Dental Medicine, Sofia, Bulgaria \\ ${ }^{2}$ Institute of Mechanics, Bulgarian Academy of Sciences, Sofia, Bulgaria
}

Summary. The use of pins in restoration of large cavities with esthetic resin materials appear in the dental literature after 1970 and there are less than 20 publications, focused around restorations of class IV cavities. The aim of the present study is to test the role of pins in the fracture resistance in class IV restorations with resin materials. Materials and methods: 68 matured human upper and lower sound front teeth are included in the study. The groups are upper incisors, lower incisors, canines with or without pins. All cavities are filled with the same resin material, technology and Prime bond NT. Termocycling: 30 days in $30^{\circ} \mathrm{C}, 100 \%$ humidity, 60 days in $100 \%$ humidity $2 \mathrm{X} 12$ hours at $35^{\circ} \mathrm{C}$ and $40^{\circ} \mathrm{C}$ and 100 dry cycles, 20 seconds each in the following order $-45^{\circ} \mathrm{C} \pm 3^{\circ} \mathrm{C}$, room temperature, $5^{\circ} \mathrm{C}$, room temperature, two series, 50 each with two days between in Cultura incubator of Viva Dent $55^{\circ} \mathrm{C}$ and ice. Machine for vertical load testing ZD 10/90, load in Newtons (N), from $20 \mathrm{~N}$ to $1275 \mathrm{~N}$, speed $0.5 \mathrm{~mm} /$ $\mathrm{min}$, displacement from 0.1 to $1.2 \mathrm{~mm}$. Type of fractures observed: adhesive, cohesive in dentine and in resin material, mixed. Results: The highest proportion of fractures observed was in front teeth with large cavities and with pins, low loading (493-503N). Front teeth with large cavities without pins have better resistance and lower proportion of fractures $(488-526 \mathrm{~N})$. Canines are more resistible with pins and less without. Lowest resistance is found in lower front teeth when pins are present. Conclusion: In class IV restorations when tissue loses are less than $2 / 3$ of the incisal ridge pins can decrease the fracture resistance of the teeth.

Key words: pins, operative dentistry, fracture resistance

\section{BACKGROUND}

$\mathrm{H}$ istory of pins dates back to 1849 , but the restoration of large cavities with esthetic resin materials with the use of pins appear in the literature since 1970 . The very small number of publications -15 publications for 44 years for class IV cavities only, is related to the difficulties in the standardization 
of in vitro studies and to the follow up procedures in the clinical studies. In the last 20 years the articles focus on adhesive build ups, with or without pins. One of the complications when pins are used are the axial and transversal forces which they have to stand. Even more complicated are the clinical cases when pins are used with posts and for core build ups. In different literature sources their indications and exclusion criteria look quite different. Some publications are even excluding pins from treatment plans, some recommend them in most class IV cavities.

According to Pickard [8], their indications are dependent on the possibility that $1.5 \mathrm{~mm}$ of the material can be obtained around the pin, with the risk related to the distance between the pin canal and the pulp, and their success rate is related to the fixation method which have to be performed with speed no more than 200. In the dental literature the tests in the last 40 years are with pins and silicate cements, glass ionomers, resin materials with and without adhesive bonding. Different are also the proportions of the missing part of the incisal ridge, like 1/3, 1/2, 2/3 or more. The performed tests are for vertical loading, comprehensive strength, etc. Most of the studies are in vitro and very few are clinical ones. Muhlbauer [6] found that pins can enhance the fracture resistance when they are used with bonded resin materials and Roberts found that they are decreasing this resistance. Butchard [1] in 1988 found that pins in in vitro testing are not equivalent to pins in real clinical situation, when they can lower the duration of every restoration. These findings are more or less related to the time when recent concepts of bonding were not that much in the dental practice and even some of the last generations of resin restorative materials were not in use.

In 1983 Garman tested the use of pins in the treatment of abrasion, Summit in 2001 and 2004 reported clinical results after 5 and 6 years of examinations of class II restorations with pins with and without bonding. This duration of clinical results has never been studied with class IV restorations.

\begin{abstract}
AIM
The aim of the present study is to test the role of pins in the fracture resistance in class IV restorations with resin materials.

\section{MATERIAL AND METHODS}

Sixty eight matured human upper and lower sound front teeth with straight roots were placed in four groups: upper incisors and canines with or without pins with two sizes of the crowns. Lower incisors group was used as a positive control group (fifth group). Class IV cavities with absence of more than $1 / 3$ and up to $2 / 3$ of the incisal ridge was prepared without any elements of conventional retentive elements. Fixation of the pins was in the middle of the gingival wall. All cavities are filled with the same resin material and technology and bonded with Prime bond NT.

Termocycling started with 30 days in $30^{\circ} \mathrm{C}$ in saline solution in $100 \%$ humidity for 60 days with 100 dry cycles, 20 seconds each in the following order $-45^{\circ} \mathrm{C} \pm 3^{\circ} \mathrm{C}$, room temperature, $5^{\circ} \mathrm{C}$, room temperature. After the wet cycling, dry cycling was performed in
\end{abstract}


two series 50 each with two days intervals in humid environment in Cultura incubator of Viva Dent $55^{\circ} \mathrm{C}$ and ice $-4^{\circ} \mathrm{C}$ with mean intervals at room temperature. Teeth lost before the loading were 7 without pins during cycling and polishing. The vertical load testing was with universal testing machine type Instron for vertical loading, load in Newtons $(\mathrm{N})$, from $20 \mathrm{~N}$, speed from $0.5 \mathrm{~mm} / \mathrm{min}$ with displacement from 0.1 . Type of the fractures registered are: adhesive, cohesive in dentine and in resin material, mixed.

Statistical analysis was performed using graphic analysis, ANOVA and Tukey post hoc analysis.

Group 1A

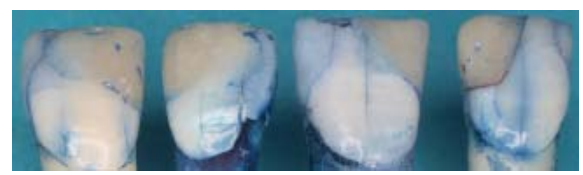

Group 1B

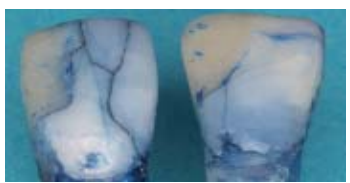

Group 2A

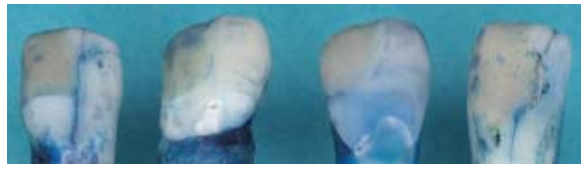

Group 2B

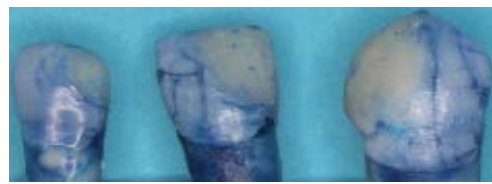

Group 5 Lower incisors

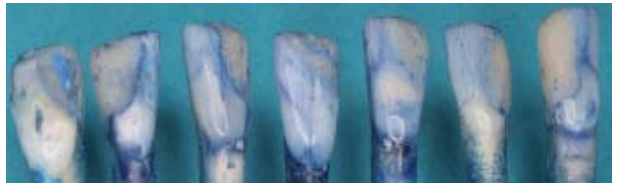

Fig. 1 a-e. Restored teeth in the groups after cycling and before the vertical loading

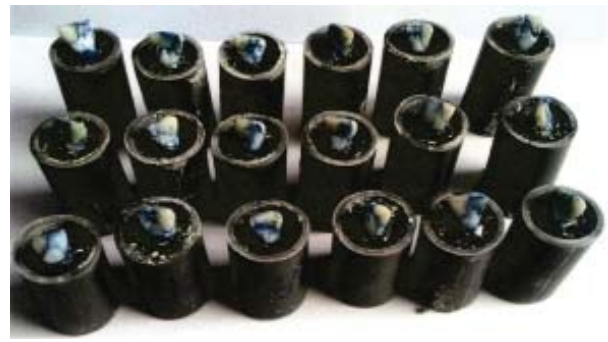

Fig. 2. Restored teeth in the groups packed and prepared for vertical loading

\section{RESULTS}

The results from the vertical loading are shown in table 1, where for all groups and numbers of teeth the fractures are shown as a total number and the load in Newtons as means. The relation between Newtons and kilograms is $1 \mathrm{kgf}=9.81 \mathrm{~N}$. 
The highest proportion of fractures are observed in front teeth with larger cavities and with pins with low loading: 50 to $51 \mathrm{kgf}$ (493-503N), although the data is not significant. Front teeth with large cavities without pins have higher resistance and lower proportion of fractures: 50 to $54 \mathrm{kgf}(488-526 \mathrm{~N})$. Canines are more resistible with pins and less without. Lowest resistance is found in lower front teeth when pins are present.

Table 1. Results from the vertical loading and fracture resistance

\begin{tabular}{|l|c|c|c|c|}
\hline Group & Teeth & Fractures & Load in N & Load in kgf \\
\hline $1 \mathrm{~A}$ & 18 & 19 & 493.23 & 50.28 \\
\hline $2 \mathrm{~A}$ & 12 & 12 & 502.76 & 51.25 \\
\hline $1 \mathrm{~B}$ & 7 & 7 & 525.54 & 53.57 \\
\hline $2 \mathrm{~B}$ & 11 & 9 & 487.86 & 49.73 \\
\hline 5 & 6 & 6 & 310.65 & 31.67 \\
\hline
\end{tabular}
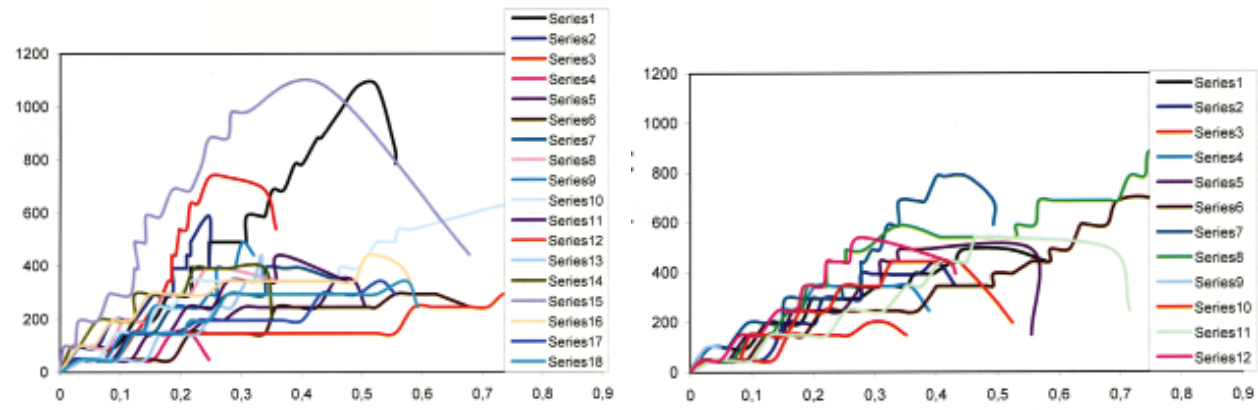

Fig. 3, a and b. Graphics of the loading tests in group $1 \mathrm{~A}$ and $2 \mathrm{~A}$
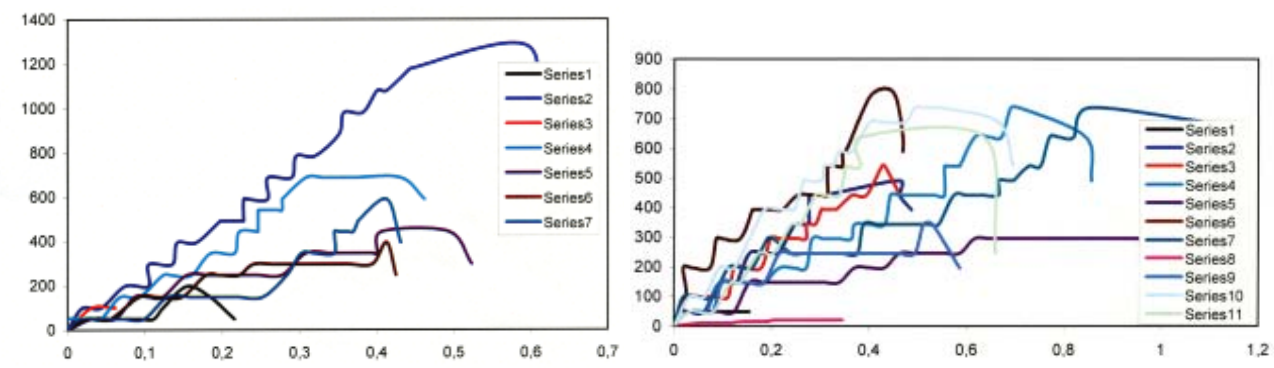

Fig. 4, a and b. Graphics of the loading tests in group 1B and 2B 


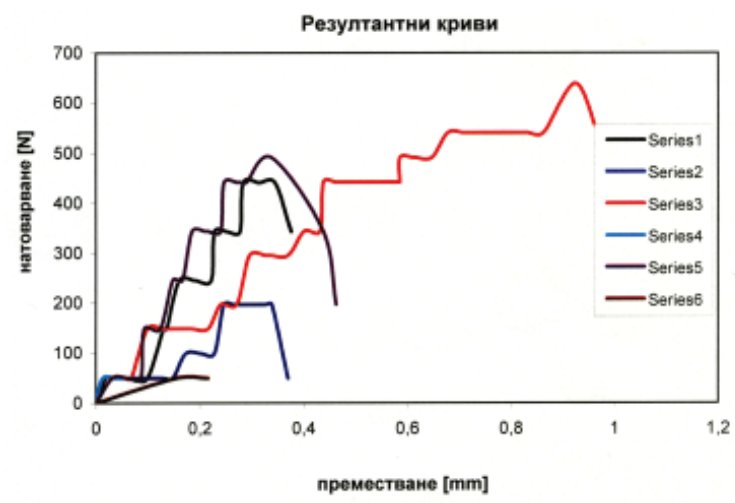

Fig. 5. Graphics of the loading tests in group 5 (control group)

\section{DISCUSSION}

Few publications described increased resistance of the restorations when pins are angled to the surface. Unfortunately, this technique is not technically applicable for most teeth and resin materials in their treatment. For some authors pins use is well motivated only when very little of enamel and dentine are present [8]. This is something we cannot agree with, because when the amount of hard tissues is very little, the fracture resistance will decrease and will be much lower. Moreover, a higher proportion of dentine defects will occur and the microleakage will be much higher. Additional difficulties can occur due to the correct placement of pins in relation to the size and shape of the crown. When pins placement is too close to the surface the fracture resistance can be compromised seriously. On the other hand, their need is always where is the insufficient amount of enamel and dentine. A comparison of $A$ and $B$ groups shows also that smaller cavities in $2 A$ and $2 \mathrm{~B}$ groups are more resistible with pins and bigger restorations are more resistible without pins. This can be explained with the higher proportion of hard tissues available for adhesive bonding and micromechanical interlocking.

\section{CONCLUSION}

In class IV restorations when tissue loses are less than $2 / 3$ of the incisal ridge pins can decrease the fracture resistance of teeth, which are with relatively smaller volume of hard dental tissues.

Acknowledgements. The present research was generously sponsored by the Student Council of the Medical University of Sofia. We are grateful for the active participation of the students from the research group in Conservative Dentistry: N. Sheinova, A. Latkovska, M. Vasileva, M. Ilieva, M. Valeova, M. Sharani, B. Radenkov, M. Mladenov, I. Ivanov, S. Stoyanov, S. Hudaim, J. Jassim and V. Ivanova. 


\section{REFERENCES}

1. B u t c h a r d, D., A. Grieve et J. Kamel. Retention of composite restorations: A comparison between a threated pin and a dentine binding agent. - British Dental J., 165, 1988, № 6, 217-219.

2. B u rge s s, J. O., A. Alvares et J. B. Summit. Fracture resistance of complex amalgam restorations. - Operative Dentistry, 22, 1997, № 3, 128-132.

3. Fe de rick, D. A marriage of convenience: bonds of retention pins and composites. - J. Prosthetic Dentistry, 57, 1987, № 3, 270-276.

4. Felt o $n, D$. et al. Pulpal response to treated pin and retentive slot techniques: A pilot investigation. - J. Prosthetic Dentistry, 66, 1991, № 5, 597-602.

5. I m bery, T. A., J. O. Burgess et R. C. Batzer. Comparing the resistance of dentin bonding agents and pins in amalgam restorations. - J. Am. Dental Association,126, 1995, № 6, 753-759.

6. Muhlbauer, J. et al. Composite pins in class IV restorations. - Operative Dentistry, 27, 2002, № $3,285-288$.

7. Neme, A., D. Evans et B. Maxson. Evaluation of dental adhesive systems with amalgam and resin composite restorations: comparison of microleakage and bond strength results. - Operative Dentistry, 25, 2000, 512-519.

8. Pickard, H. M. A manual of operative dentistry. Oxford University Press, 1983, p. 129, 149, 153, 204, 206, 232.

9. Redtenbacher, K. Use of retentive pins in composite restorations class IV. - Quintessence International, 1975, 6, 7, 31-32.

10. Roberts, H., C. Hermesch et D. Charlton. The use of resin composite pins to improve retention of class IV restorations. - Operative dentistry, 25, 2000, 4, 2, 270-273.

11. S e n, D., E. Nayir et F. Cetiner. Shear bond strength of amalgam reinforced with a bonding agent and/or dentin pins. - J. Prosthetic Dentistry, 87, 2002, № 4, 446-450.

12. St andle e, J., E. Collard et A. Caputo. Dentinal defects caused by some twist drills and retentive pins. - Journal of Prosthetic Dentistry, 24, 1970, № 2, 185-192.

13. Su m mitt, J. B.et all. The performance of bonded versus pin retained complex amalgam restorations: a five year clinical evaluation. - Journal of American Dental Association, 132, 2001, № 7, 923-931.

14. Sum mitt, J. B.et al. Six year clinical evaluation of bonded and pin-retained complex amalgam restorations. - Operative Dentistry, 29, 2004, № 3, 261-268.

15. Te re nce, A., et al. Comparing the resistance of dentin bonding agents. - J. Am. Dental Association, 126, 1995, 753.

16. Vaught, R. L. Mechanical versus chemical retention for restoring complex restorations. What is the evidence? - J. Dental Education, 71, 2007, № 10, 1356-1362.

- Corresponding author:

Dr. E. Boteva

Faculty of Dental Medicine

1, Sv. G. Sofiisky St.

Bg-1431 Sofia

e-mail: e_boteva@abv.bg 